\title{
The Relationship between the Educational Fascinations of Students with Educational Self-Actualization (Case Study: Students of Secondary Education Course in Isfahan City)
}

\section{Zohreh Esmaeili}

\author{
Assistant professor, Department of Educational Sciences and Psychology
}

Payame Noor University (PNU), Tehran, Iran

\section{Simin Naghsh}

PhD student in planning distance education. Department of Educational Sciences and Psychology Payame Noor University (PNU), Tehran, Iran

\author{
Doi:10.5901/mjss.2015.v6n6s6p284
}

\section{Abstract}

This article investigate the relationship of educational infatuation and educational Self-actualization. To select sample size, 382 person were chosen with randomly sampling method. And completed a researcher-made questionnaire of educational infatuation comprising four aspects of manifested educational motivation, expressed educational motivation, tested educational motivation, and listed educational motivation and questioner Self-actualization with 16 items. Reliability of these question are with Cronbakh Alfa method were (0/74) for educational creativity and (0/80) for Self-actualization. The face validity of two questioner was investigate. Then data analysed with correlation and step by step regression. The results showed that there were significant relationship between manifested educational motivation, expressed educational motivations, tested educational motivation, and listed educational motivation with educational Self-actualization. The results of stepwise regression showed that educational Self-actualization is explained by manifested educational motivation, expressed educational motivation, tested educational motivation, and listed educational motivation.

Keywords: infatuation, manifested educational motivation, expressed educational motivation, tested educational motivation, and listed educational motivation, Self-actualization

\section{Introduction}

Educational self-actualization of students and realization of their educational talents are one of the higher goals of teaching-learning systems. Education experts have always tried to provide the conditions so that their students show the highest performance (Talebpour, 2002). Self-actualization requires self-awareness. Schools, high schools, and universities should make students aware of their abilities and talents. They should know this fact at the beginning of their education that they make uniqueness on their own and they will have a unique future. When the student became mature, uniqueness basis should be deepened and completed in him. He should realize the uniqueness of each of surroundings people from the first year of school. Without belief in life for self-actualization and helping other to flourish themselves, trying to self-address leads to a kind of unhealthy narcissism (Lotfabadi, 2000). Self-actualization in humanistic psychology means to realize the maximum potential of the individual by himself. Self-actualization refers to the phenomenon that people tend to go beyond their basic needs i.e. the needs which are listed in the Maslow's hierarchy of needs, progress. People try to use the facilities in an optimal way through self-actualization and flourish all their hidden talents. As Abraham Maslow states: "What man could be, should be." What is important in the learning process is educational self-actualization. In fact, educational self-actualization means that students achieve their qualifications during the education and learning process on their own and realize their potential educational and learning talents. But what should be noted is that educational self-actualization is not possible without regarding the effectiveness variables which are applied on them and they should always be considered. Self-actualize people are able to recognize their talents and try to flourish them and achieve the optimal levels of individual performance. According to Maslow's definition of self-actualization is: Audacity, autonomy, and move to the new experience, capability to live in the moment, high selfrecognizing and self-control. Such a person is known among people as a complete person who has the personal satisfaction of life (Goldstein, 1993).

Soleymani studies (2005), have shown that educational fascination has a relationship with educational self- 
actualization. The self-actualization basis of students is learning the motivation and educational fascination. The role of students' attention to learning has been always considered (Anderson, 1987). According to Abedi (2008) and Morrison (1926), the most common cause for the lack of learning in students is less attention to them. In fact, attention to them in learning process makes their talents actualized and lack of attention to them leads to reluctance for learning and ultimately, lack of talent flourishing. In order to create vitality and development in students, their quality of education and enthusiasm and understanding should be considered and their hidden talents should be manifested. In such a case, their intrinsic motivation grows and achieves the higher levels of learning goals which is self-actualization (Lotfabadi, 2000).

\section{Research Literature}

One of the important tasks of the education system is creating self-actualization in the students' minds. Self-actualization can be considered as self-expression as a unique character. According to Moghaddam et al. (2008) and Shavaran (2006), although, most of the students have an intelligence above the average level and they have a significant learning capacity, but, they suffered from educational anorexia and they cannot have a good educational performance only for some reason such as lack of motivation, lack of perseverance, lack of confidence, lower sense of self-worth, shyness, lack of positive motivation, etc. For this reason, their educational talents are not flourished as their merit. On the other hand, according to Maslow, a self-actualized person has certain goals. He moves toward them and tries to understand them. He thinks to make the future and he can create a link between the present, the future, and the past. A selfactualized person has a great need for mental simulations so that he gets help from his intelligence and goes toward unknown things and he has a high acceptance for new experiences (Schakter et al., 2011). The term of self-actualization is first used by Gould Kurt Stein". In his opinion, it is the main motivation and in fact, the only real motivation of an individual and other motivations are merely its manifestation (Cooper, 1998). "Yong" considered individuality synonymous with self-realization. This means the integration of heterogeneous elements in the personality and turning it into a harmonious and unique model. Characteristics that Yong has counted for individuality are as following:

- People who have reached individuality are in middle age because they have left behind the severe crises that the main personality transformation is at this time.

- They have reached the higher stages of self-knowledge. The people who have reached individuality themselves with all the weaknesses and shortcomings.

- Their third characteristic is integration in the personality.

- The fourth is accepting the human nature. For this reason, they have more empathy with other human beings. The purpose of human nature is whatever the truth of being human is. Human nature has a series of strengths and weaknesses. He has his own special power for intellection, emotions and excitement. Also, human nature has certain natural forces which are known as instinct.

- The fifth is that he does not fear of the unknown. These unknown things cover unreasonable factors, what is not match with reason and logic and metaphysical phenomena (Ames, 1990).

In Maslow's opinion, self-actualization means having the greatest and most obvious experiences with the most concentration and absorption. A self-actualized person is very open-minded and he can learn new and positive tips from anyone and any situation without having need for class, lesson, and books. Such a person can control the internal rules. He lives healthier and better and enjoys the life experiences deeply (Glitman et al., 2004).

Maslow believes that we should study the samples of a human who are the most innovative, safest and most developed instance of the people to understand the nature of human being. For this reason, he chose a small group of prominent people like Abraham Lincoln, Albert Einstein, William James and etc. and studied their biography. After that, he achieved a multi-dimensional image of self-actualization and self-actualized individuals like characteristics of the selfactualized individuals, the role of meta-needs in self-actualization, behaviors that lead to self-actualization, and causes of disability in the self-actualization (translated by Omidian, 2006).

After studying his small group, Maslow mentioned twelve characteristics of self-actualized individuals which are: Very efficient perception of reality, acceptance of himself, others, and the nature in general, simplicity and naturalness, focusing on the problems instead of himself, the need for independence and privacy, feeling fresh and consistent understanding, mystical experiences, social interest, interpersonal relationships, being creative, democratic character structure, and resistance to acculturation. This collection truly is an amazing set of characteristics and introduces these people sacred, but, these people are not always perfect and in fact, they have disadvantages. Maslow found that they sometimes become too rude and even exceptionally cruel, bitter, and cold. They also have moments of doubt, fear, and guilt sense but, but these events in their behavior certainly is exceptional and occur less (Gholami, 2006).

However, it must be said that the lack of educational vitality and pale fascination of students cause that the 
students do not reach their high-level goals which are verily self-actualization. Studies have shown that educational fascination in the form of educational interest can be investigated.

Motivation is an inherent phenomenon which is affected by four factors, i.e., the position (the environment and external stimuli), bowel (state and internal status of organism), target (treatment, purpose and approach), and tools (tools to reach the target). Human beings acquire their necessary motivation to achieve their goals, needs and instincts. Regarding the knowledge seekers and students, motivation of educational achievement has a great importance because educational achievement leads to self-actualization. With this incentive, individuals pursue the necessary mobility for the successful completion of a task, reach the goal or achieve a certain degree of competence in their work until they can acquire the required success in learning and educational achievement. Therefore, it can be said that motivation shows the reasons for people's behavior and identifies that why they act in a particular way (Frank et al., 2008). Motivated behavior is a behavior with energy, direction, and trail. From the educational perspective, motivation is a multifaceted structure that is associated with learning and educational achievement. There are several interpretations and differences for motivation. In the field of education, motivation is a three-dimensional phenomenon encompassing individual beliefs about performing the desired activity, reasons or purposes of the individual to perform that activity, and emotional reactions associated with that activity (Goldstein et al., 2009). Their findings showed that the personality, family, educational, and social variables are linked with this structure. On the other hand, the researchers consider the low rate of variables of hope to the future, self-esteem, quality of educational factors, household income, and marital status as the main factors for the reduction of educational motivation. In line with these findings, researchers believe that training should be provided in a sufficient space with proper facilities relevant to learners' needs to create interest and motivation. According to Lavassani et al. (2007), achievement motivation has been suggested by David McClelland et al. (1961) and John Atkinson (1965). Ballou et al. (2006) have done a research about achievement motivation and its impact on school students. The results showed that there is a positive relation between the achievement motivation scores and grades. Mitchell (1992) has performed a research regarding the relationship between achievement motivation and educational achievement and showed that there is a significant relationship between them. According to the Nezami (1997), Newman and Rachel (1988) also showed that there is a relatively strong relation between achievement motivation and the scores of university courses. Vallerand (1992) believes the student's interest and motivation in learning play both roles of cause and effect. This means that the learner who is interested in the topic reached more success on a scale of a low interest learner and this success increases their interest level and motivation towards a subject. Schiefele 91992) believes in the book of psychology for training that if students be guided in this direction that they relate their success and failure to their personal efforts, success motivation can be increased in them. Maslow considers achievement motivation resulted from meta-needs and believes that, contrary to the shortcoming needs that originate from the exclusion of human beings, meta-needs acquire their power from the human desire to grow and flourish. Meta-needs is achieving to what it has in the maximum power and talent. Self-actualization needs curiosity, eagerness to learn, recognition, and etc. At this stage, human tries to discover his abilities and talents and fulfill his aspirations. Maslow the characteristics of self-actualized individuals: 1. Having a good understanding of reality, 2. The ability to accept himself and others, 3. Being normal, 4. Being problem-oriented instead of self-orientation, 5. Being interested in solitude and privacy, 6 . Resistance against problems with others, 7. Communion toward others (Saif al, 1386). According to Saif (2008), Geij and Bellamy (1992) have defined the achievement motivation as a desire or interest to the overall success or success in a specific field of activity.

According to what was said the main purpose of this study was to test the following hypothesis:

1. There is a relationship between the educational fascination (declared educational interest) and educational self-actualization.

2. There is a relationship between the educational fascination (expressed educational interest) and educational self-actualization.

3. There is a relationship between the educational fascination (tested educational interest) and educational selfactualization.

4. There is a relationship between the educational fascination (listed educational interest) and educational selfactualization.

\section{Research Method}

The present study is practical in term of purposes, quantitative in term of data, and correlational study in term of the nature and type. Because we evaluate the impact of independent variables on the dependent variable without manipulating it. 
Statistical population, sample and sampling method: The studied statistical population in this research was all high school boy students of private schools in Isfahan at the school year of 2014-15 over 8789 persons. 382 persons were selected for the sample group using multi-stage cluster sampling method with Morgan table.

Measurement tools: the following tools were used to collect data.

1. Questionnaire of educational fascination including four dimensions of declared educational interest (items 1 to 5), expressed educational interest (items 6 to 10), tested educational interest (items 11 to 15), and listed educational interest (items 16 to 20).

2. Questionnaire of educational self-actualization including sixteen items and four dimensions. Cognitive dimension items 1 to 6), emotional dimension (items 7 and 11), and mental-motion dimension (items 12 and 16).

\section{Findings}

The results of the present study will be presented in two parts as follows.

A) Data description: Descriptive statistics are used in this section.

Table 1. Descriptive indices of the variables

\begin{tabular}{|l|c|c|c|c|c|c|}
\hline Variables & Minimum & Maximum & Mean & S.d. & Obliquity & Kurtosis \\
\hline Self-actualization & 2 & 4 & $3 / 44$ & $0 / 44$ & $0 / 50$ & $-0 / 23$ \\
\hline Declared educational interest & $1 / 80$ & 5 & $3 / 49$ & $0 / 63$ & $-0 / 23$ & $-0 / 23$ \\
\hline Tested educational interest & 1 & 5 & $3 / 58$ & $0 / 68$ & $-0 / 46$ & $0 / 37$ \\
\hline Expressed educational interest & $0 / 80$ & $2 / 50$ & $1 / 75$ & $0 / 34$ & $-0 / 34$ & $-0 / 3$ \\
\hline Listed educational interest & $1 / 60$ & 5 & $3 / 44$ & $0 / 66$ & $-0 / 23$ & $-0 / 19$ \\
\hline
\end{tabular}

B) Data analysis: correlation and regression tests were used in this section Initially, the correlation between the variables is evaluated.

Table 2. Pearson correlation coefficient results of evaluating the relationship between the educational fascination (declared educational interest, expressed educational interest, tested educational interest, and listed educational interest) and educational self- actualization

\begin{tabular}{|l|l|c|c|c|}
\hline Dependent variable name & Independent variable name & Correlation coefficient & Significance level & Interpretation \\
\hline educational self- actualization & Declared educational interest & $0 / 48$ & $0 / 001$ & Direct and significant \\
\hline educational self- actualization & Expressed educational interest & $0 / 57$ & $0 / 001$ & Direct and significant \\
\hline educational self- actualization & Tested educational interest & $0 / 49$ & $0 / 001$ & Direct and significant \\
\hline educational self- actualization & Listed educational interest & $0 / 56$ & $0 / 001$ & Direct and significant \\
\hline
\end{tabular}

As can be seen in the above table, the relationship of declared educational interest (0.48), expressed educational interest (0.57), tested educational interest (0.49), and listed educational interest (0.56) with educational self- actualization is significant and positive at 0.001 level.

In the following, the inter-regression method was used to evaluate that how much of the educational fascination components (declared educational interest, expressed educational interest, tested educational interest, and listed educational interest) are able to predict the educational self-actualization.

Table 3. Summary of the self-actualization regression analysis

\begin{tabular}{|c|c|c|c|}
\hline $\mathbf{R}$ & $\boldsymbol{R}^{\mathbf{2}}$ & Adjusted $\boldsymbol{R}^{\mathbf{2}}$ & Estimation standard error \\
\hline 0.68 & 0.46 & 0.46 & 0.32 \\
\hline
\end{tabular}

According to the specified values in the above table, educational fascination explains about 46 percent of educational self- actualization changes which is a significant amount.

In the following ANOVA test was used to investigate the significance of the regression test. In other words, this test was done to clarify that whether the predictive variables (declared educational interest, expressed educational interest, 
tested educational interest, and listed educational interest) can be effective in predicting the criterion variable of educational self-actualization or not. The results of this test are presented in the following table.

Table 4. ANOVA analysis of predictive factors

\begin{tabular}{cccccc}
\hline Model & Total of squares & df & Mean of squares & F & Significance level \\
\hline Regression & $34 / 67$ & 4 & $8 / 67$ & & \\
\cline { 1 - 4 } Error & $39 / 77$ & 377 & $0 / 10$ & $82 / 17$ & 0 \\
\hline Total & $74 / 45$ & 381 & & & \\
\hline
\end{tabular}

As can be seen in the above table, the obtained F-value at the 0.001 level is significant. This shows that the impact of one of the predictor variables is significant on the criterion variable. In the following, we will evaluate the impact of each variable.

Table 5. Regression coefficients of educational self-actualization

\begin{tabular}{lccccc}
\hline & $\boldsymbol{\beta}$ & Error & Beta & $\mathrm{t}$ & Significance level \\
\hline Constant value & $1 / 45$ & $/ 110$ & - & $12 / 82$ & $/ 0010$ \\
declared educational interest, & $/ 070$ & $/ 030$ & $/ 100$ & $2 / 17$ & $/ 0010$ \\
expressed educational interest, & $/ 360$ & $/ 060$ & $/ 280$ & $5 / 72$ & 10010 \\
tested educational interest, & $/ 140$ & $/ 020$ & $/ 230$ & $5 / 18$ & $/ 0010$ \\
and listed educational interest & $/ 160$ & $/ 030$ & $/ 240$ & $5 / 06$ & 10010 \\
\hline
\end{tabular}

As can be seen in the above table, the relationship between educational fascination (declared educational interest, expressed educational interest, tested educational interest, and listed educational interest) and educational selfactualization is significant and according to the obtained coefficients in the table, the regression equation for the criterion variable (educational self-actualization) can be written as follows:

$$
b_{1} x_{1}+\text { a constant value }=\hat{y}
$$

$=1.45+0.28$ (expressed) +0.24 (tested) +0.23 (declared) +0.1 (listed) self-actualization

Thus, it can be concluded that educational fascination components (declared educational interest, expressed educational interest, tested educational interest, and listed educational interest) have a significant contribution to the prediction of educational self-actualization that in the meantime, expressed educational interest is more important.

\section{Discussion and Conclusion}

The results showed that there is a significant relationship between the educational fascination (declared educational interest, expressed educational interest, tested educational interest, and listed educational interest) and educational selfactualization. Conducted evaluations have shown that there is a significant relationship between factors such as educational fascination and educational success with educational self-actualization (Houman, 1987; Fardanesh, 2004; Natayej Ansari and Skrouchi, (2006). (Shahsavani, 1379) has shown that educational fascination can be investigated in the form of educational interest. Educational interest of students can be traced in different forms such as the declared interest, expressed interest, tested interest, and finally, listed interest by the students. Educational fascination is as an effective factor on the educational actualization. Askari (2004) showed in the investigation of the students' motivation decline resources that appropriate fulfilling the initial and secondary physiological needs means access to welfare facilities, jobs, and appropriate income in the future. Also, non-compliance using of facilities and present educational level for university students in whole groups has caused remarkable motivational deficiencies. As a result, motivational deficiencies may cause a kind of pessimism, anxiety, and depression in one hand and lack of self-actualization on the other hand.

Amini et al. (2002) have shown that in the field of internal factors affecting the learning motivation of clinical students, the highest averages respectively were related to merit and talent of students in clinical learning, students' interest in the course, and student's personality traits and in the field of external factors affecting the learning motivation of clinical students, the highest averages respectively were related to the interest of teachers to train, occupational and social status of graduates and encourage.

Greense (1989) found out in his study that students who had low self-esteem experienced more negative effects 
against their poor performance in the exam compared with students who had higher self-esteem so that their poor performance leads to the lack of motivation to the course and they extend they lack the motivation to the next exams (Soleymani, 2005).

Hamburg and Sartorius (1989) found in their study that whatever the students have more motivation in their education, their self-esteem increases. Such people try in new positions and gain new successes that will increase their self-esteem (Karbasi and Vakilian, 2003). Finally, educational motivation and fascination are required to create educational self-actualization which is one of the main goals in education.

\section{References}

Amini, Abolghasem; Valizadeh, Susan; Mohammadi, Batool. (2002). "Evaluating the factors affecting learning motivation of clinical students and providing appropriate methods to strengthen their motivation from the perspective of the faculty of Tabriz University of Medical Sciences", abstracts Fifth National Conference Medical Education.

Ames CA. (1990). "Motivation: What teachers need to know? Teach Coll Rec". 91(3):409-21.

Anderson, James, G. (1987)."Structural equation models in the social and behavioral Sciences: model building". Child Development, 58, 4964 .

Ansari E W, Oskrochi R. (2006)."What matters most? Predictors of student satisfaction in public health education courses". Public Health, pp462-473.

Ballou, K. (2009). Language learner experiences in an online virtual world. The JALT CALL Journal, 5(2), 61-70

Cooper, H., Lindsay, J. J., Nye, B., \& Great house, S. (1998). "Ralationship among Attitudes abouthomework, amount of homework assigned and completed and student achievement"Journal of Educational Psychology, 90 (1), $70 \_83$.

Frank D. Cox, Human Intimacy (2008) p. 72

Goldstein, A.; Brandon, M. (2009) Reclaiming Desire p. 232

Goldstein, A. (1993). Quoted in Arnold H. Modell, the Private Self (Harvard 1993) p. 44

Gleitman, Henry; Fridlund, Alan J. and Reisberg Daniel. (2004). Psychology. 6th Ed. New York: Norton \& Company.

Mitchell, J. V. Jr. (1992). "Interrelationships and predictive efficacy for indices of intrinsic, extrinsic,and self-assessed motivation for learning" Journal of Research and Development in Education 25 (3),149-155.

Vallerand, R.J., Pelletier, L.G., Blais, M.R, Brière, N.M., Senécal, C., \& Vallières, E.F. (1992). The academic motivation scale: a, extrinsic, and amotivation in education. Educational and measure of intrinsic, Psychological Measurement, 52, 1003-1017

Schacter, Daniel L., Gilbert, Daniel T., and Wegner, Daniel M (2011). "Human Needs and Self-ctualization". Psychology; Second Edition. New York: Worth, Incorporated, 2011. 486-487.

Santrak, James W. (2001). "Educational Psychology", Translated by: Morteza Omidian, (1385), Yazd, Yazd University Press.

Soleimani, Afshin. (2005). "Creative class", published by parents and educators Forum publication.

Saif Ali Akbar. (2007). "Measuring evaluation and educational assessment", Tehran time publication.

Saif Ali Akbar. (2008). "The new educational psychology", Sixth Edition, Second Edition, Tehran time publication.

Shahsavani, Soudabeh. (2000). "Investigating the causes of defections in motivation to study in high school students in Isfahan", Research Council of Education Research Department of Isfahan province.

Talebpour, Akbar; Nouri, Abolghasem; Maulavi, Hussein. (2002). "The impact of cognitive training on Locus of Control, achievement motivation and educational achievement of control students" Journal of Psychology, 21, the sixth year, the number 1, Spring.

Abedi, Ahmed. (2008). "Evaluating the relationship between the educational achievement of high school boys and girls in Isfahan with their personality characteristics" Research project of the Education Research Council of Isfahan

Asgari, Parviz; Hassan Ahadi, Hassan; Mazaheri, Mohammad Mehdi; Enayati, Mirsaleh Al-Din; Heydari, Alireza. (2007).

Servant, Younes. (2006). "The relationship between achievement motivation and self-concept with educational achievement of students in the eighth grade science class based on the results of the Thames -R ", Journal of Iranian Psychologists, Issue 7, Islamic Azad University, South Tehran.

Karbasi, Manijeh and Vakilian, Manouchehr. (2003). "Adolescents and youth issues", Tehran, Payam Noor University.

Lotfabadi, Hussein. (2000). "Applied Developmental Psychology", Tehran: National Youth Organization, first printing.

Lavassani, Gholam Ali; Keyvanzadeh, Mohammad; Keyvanzadeh, Hedyeh. (2007). "The relationship between educational activities, educational achievement motivation, emotional intelligence, and contextual variables with the educational achievement of student", Journal of Psychology and Educational Sciences, Tehran University, thirty-seventh year, the first issue.

Masaeli, Saeid. (2007). "Achievement Motivation of champions in Championships", BS.c thesis, Islamic Azad University of Tehran.

Moghaddam, Azam; Nikbakht, Akram; Nikneshan, Shaghayegh; Siadat, Seyyed Ali. (2008). "Evaluating the relationship between emotional intelligence and creativity of the students", Journal of Educational Psychology, Vol. 4, No. 7, Summer 1387, pages 99112.

Hooman, Heidar Ali. (1987). "Evaluating the causal models of educational attainment", Journal Educational Sciences, 10 (2-1), $19-39$.

Nezami, Amir. (1997). Evaluation of some social and psychological factors affecting the educational performance of high school students in Tabriz. MA thesis, Shahid Bahonar University, Faculty of Humanities.

Ghassem Abedi, Farideh Rostami, Rezaali Mohammadpor, Abdolazim Nejatizadeh, Tasnim Eghbal Eftekhaari,Hamid Reza Miri, Nasrin Tayyari, Ali Alizadeh (2012). Phenomenology of Scientific Board's Views about Electronic Learning, Life Sci J 2012; 9(4):535539. 